\title{
Poor correlation between intracranial pressure and intraocular pressure by hand-held tonometry
}

This article was published in the following Dove Press journal:

Clinical Ophthalmology

7 June 2013

Number of times this article has been viewed

\author{
Shani Golan' \\ Shimon Kurtz' \\ Daphna Mezad-Koursh' \\ Michael Waisbourd' \\ Anat Kesler' \\ Pinchas Halpern ${ }^{2}$ \\ 'Department of Ophthalmology, \\ Tel Aviv Sourasky Medical Center, \\ affiliated with the Sackler Faculty \\ of Medicine, Tel Aviv University, Tel \\ Aviv, Israel; ${ }^{2}$ Emergency Medicine, \\ Tel Aviv Sourasky Medical Center, \\ affiliated with the Sackler Faculty of \\ Medicine, Tel Aviv University, Tel Aviv, \\ Israel
}

Purpose: The aim of this study is to provide data on the controversial issue of whether handheld measurements of intraocular pressure (IOP) are capable of accurately predicting elevated intracranial pressure (ICP) in patients undergoing lumbar puncture (LP).

Methods: All patients over the age of 18 years who underwent an LP in the emergency or neurological departments at the Tel Aviv Medical Center for any reason between October 2007 and July 2010 were eligible to participate in this prospective observational pilot study. IOP was measured with the Tono-Pen XL while patients were in the supine position before undergoing LP. ICP was measured in the lateral recumbent position. ICP and bilateral IOP were measured, and the mean and maximum values of IOP were calculated. The association between ICP and each one of the four IOP measures was evaluated by the Pearson correlation coefficient.

Results: Twenty-four patients (mean age $37.8 \pm 15.8$ years, ten males and 14 females) were enrolled. The reasons for their requiring an LP were headache (19/24 patients), evaluation for hemiparesis (2/24), cognitive deterioration (1/24), and seizures $(2 / 24)$. Nine had elevated mean opening pressure $\left(>20 \mathrm{~cm} \mathrm{H}_{2} \mathrm{O}\right)$, six had an elevated mean IOP $(>20 \mathrm{mmHg})$, and four of these six also had an elevated opening pressure. There was no significant correlation between the ICP measurements and any of the IOP measurements.

Conclusion: Handheld ocular tonometry has poor sensitivity and specificity for the prediction of increased ICP and is not an effective tool for screening for ICP in the ED or in the neurology department.

Keywords: ocular tonometry, Tono-Pen, IOP, intraocular pressure, ICP, intracranial pressure

\section{Introduction}

Emergency department (ED) physicians routinely evaluate patients with suspected increased intracranial pressure (ICP). ICP may be elevated due to hemorrhage, edema, inflammation, infection, malignancy, hydrocephalus, pseudotumor cerebri, and so on. A lumbar puncture (LP) is the usual procedure used to measure ICP. This procedure is painful for the patient and has a finite likelihood of complications, such as infection, bleeding, and postprocedure headache. It is also time consuming and occasionally difficult to execute properly. A noninvasive method to determine the presence of elevated ICP would be very useful clinically, potentially sparing some patients further radiographic or invasive testing for conditions causing increased ICP, as well as helping to identify patients with only subtle symptoms of a life-threatening condition. Several authors suggested that intraocular pressure (IOP) directly reflects ICP, and that IOP measurement may be used as a surrogate for ICP. ${ }^{1-3}$
Correspondence: Shani Golan

Department of Ophthalmology,

Tel Aviv Medical Center,

6 Weizmann Street,

Tel Aviv 64239, Israel

Tel +97236973408

Fax +97236973 867

Email shanigol2@walla.com 
A number of studies have suggested that noninvasive measurement of IOP is highly sensitive, but these examinations were conducted on patients in neurosurgical or trauma intensive care units, and all the patients had invasive intracranial monitoring devices. ${ }^{1,3}$ The goal of this study was to determine the sensitivity and specificity of noninvasive, handheld tonometry for identifying patients with elevated ICP in the setting of the ED.

\section{Methods}

This prospective, observational study was approved by the institutional review board at the Tel-Aviv Medical Center and was conducted from October 2007 to July 2010. The medical center is a large tertiary care institution whose ED has an annual census of 180,000 people. All patients over the age of 18 years who were able to give consent and were undergoing an LP for any reason were eligible to participate. Patients were excluded if they could not provide informed consent, if opening pressure could not be measured during the LP procedure, or if the physician could not perform the LP with patients in the lateral recumbent position. Consecutive patients who met inclusion criteria were enrolled on a convenience basis.

After providing informed consent, the patients were placed in a supine position and two drops of tetracaine were placed in each eye as anesthetic. The IOP was measured with the Tono-Pen XL (Reichert, Inc, Depew, NY, USA) before the LP was attempted. The device is a handheld tonometer with an IOP measurement accuracy of $\pm 5 \mathrm{mmHg}$, approaching that of the Goldmann's applanation tonometer. ${ }^{4-8}$ It was calibrated every morning and before each use. IOP was always measured twice in each eye before LP, and the average of the two values was used for analysis. The handheld Tono-Pen is a more reliable method to measure IOP, and it is more convenient and assessable for use in the ED than the Goldmann tonometer.

Opening pressure during the LP in the lateral recumbent position was considered a surrogate marker for ICP. ${ }^{9}$ LP measurements were taken by an experienced neurologist who used the standard upright water manometers that are supplied in the LP kits.

Data on the participant's age, gender, past medical history, medications, allergies, chief complaint, IOP measurement in each eye, mean IOP per eye, opening pressure of the LP, cerebrospinal fluid (CSF) analysis, and any advanced radiographic studies (eg, computed tomography or magnetic resonance imaging) were recorded. Ophthalmology residents with experience (at least 50 measurements) in handheld tonometry performed the IOP measurements.
The Tono-Pen XL has three options for IOP measurement accuracy: $\pm 20 \mathrm{mmHg}, \pm 10 \mathrm{mmHg}$, or $\pm 5 \mathrm{mmHg}$. Only measurements that achieved an accuracy of $\pm 5 \mathrm{mmHg}$ were accepted by the physician performing the procedure. IOP was considered elevated if it was $>20 \mathrm{mmHg}$. Opening pressure was considered to be elevated if it was $>20 \mathrm{~cm} \mathrm{H}_{2} \mathrm{O} .{ }^{1,3,4}$ Positive CSF was defined as a white blood cell count $>5 / \mathrm{mm}^{3}$, protein $>45 \mathrm{mg} / \mathrm{dL}$, glucose $<50 \mathrm{mg} / \mathrm{dL}$, the presence of bacteria on Gram stain, the presence of viral antigens, or the presence of cryptococcal antigen. Negative CSF was defined as a white blood cell count $<5 / \mathrm{mm}^{3}$, protein $<45 \mathrm{mg} / \mathrm{dL}$, glucose $>50 \mathrm{mg} / \mathrm{dL}$, absence of bacteria on Gram stain, absence of viral antigens, and absence of cryptococcal antigen.

The primary outcome variable was the number of patients with a mean IOP $>20 \mathrm{mmHg}$ who also had an opening pressure $>20 \mathrm{~cm} \mathrm{H}_{2} \mathrm{O}$ on LP. The sensitivity and specificity, as well as the positive predictive and negative predictive values were evaluated.

\section{Data analysis}

The ICP and IOP values for each eye (IOP: right eye, IOP: left eye) were measured in 24 patients. The mean (MEAN IOP) and maximum (MAX IOP) IOP values were calculated, and the association between ICP and each of the four IOP measurements was evaluated by the Pearson correlation coefficient. The MEAN IOP parameter was dichotomized into $0=$ MEAN IOP $\leq 20$ and $1=$ MEAN IOP $>20$. Comparison of the ICP values between the two groups was conducted by the $t$-test.

\section{Results}

The average \pm standard deviation (SD) age of the ten males and 14 females who comprised the final study cohort was $37.8 \pm 15.8$ years. The reasons for their requiring an LP were headache (19/24 patients), evaluation for hemiparesis $(2 / 24)$, cognitive deterioration (1/24) and seizures (2/24). Forty patients were originally screened for this study: 13 refused to participate and three were unsuitable because LP was not done in the lateral recumbent position $(2 / 3)$, or because of corneal erosion (1/3). All of the 24 remaining patients had a successful LP in the lateral recumbent position. Nine of them had a mean opening pressure of $>20 \mathrm{~cm} \mathrm{H}_{2} \mathrm{O}$, and six had a MEAN IOP $>20 \mathrm{mmHg}$. Four of the six patients with an elevated IOP had an elevated opening pressure. Only one patient had an elevated IOP, an elevated ICP, and a positive $\mathrm{CSF}$, and was diagnosed as having viral meningitis.

Assessments by the Pearson correlation coefficients revealed no statistically significant correlations between 
Table I Correlation between ICP and IOP in the right and left eye

\begin{tabular}{lllll}
\hline & $\begin{array}{l}\text { IOP: right } \\
\text { eye }\end{array}$ & $\begin{array}{l}\text { IOP: left } \\
\text { eye }\end{array}$ & $\begin{array}{l}\text { Maximum } \\
\text { IOP }\end{array}$ & $\begin{array}{l}\text { Mean } \\
\text { IOP }\end{array}$ \\
\hline Intracranial pressure & 0.27 & 0.20 & 0.30 & 0.27 \\
Intracranial pressure & 0.19 & 0.36 & 0.15 & 0.20 \\
\hline
\end{tabular}

Note: Numbers are $P$-values of the correlation found by Pearson correlation coefficients. $I O P=$ in $\mathrm{cm}_{2} \mathrm{O}$.

Abbreviations: ICP, intracranial pressure; IOP, intraocular pressure.

ICP and any of the IOP measurements (right and left eye, maximum IOP measured, and mean IOP). Results are summarized in Table 1, and a scatter plot of the results of these measures is presented in Figure 1.

ICP measurements in the two groups of measured IOP (below and above $20 \mathrm{mmHg}$ ) were also not statistically significant (results are presented in Table 2).

\section{Discussion}

Of the 24 patients in this study, only four who had elevated (greater than $20 \mathrm{~cm} \mathrm{H}_{2} \mathrm{O}$ ) opening pressure on LP also had elevated IOP values as measured by handheld tonometry, indicating poor sensitivity and specificity for the screening of patients with elevated ICP in the ED.

Theoretically, an increase in ICP could be transmitted to the optic nerve, and thus indirectly to the eye itself. Several studies in the literature that sought an association between IOP and ICP proposed three theories to explain such a link. ${ }^{10-12}$ The first is based on the observation that the subarachnoid space surrounding the optic nerve is a direct extension of the subarachnoid space around the brain, with which it is normally in direct communication. Any additional pressure transmitted to the eye from the subarachnoid space could potentially increase IOP above the normal range. ${ }^{1,2}$ The second theory was that IOP may become elevated as increased CSF passes by the sheath of the optic nerve, exerting pressure on the central retinal vein. ${ }^{1,2}$ The central retinal vein runs in the axial portion within the optic nerve for about $8 \mathrm{~mm}$ to $15 \mathrm{~mm}$, exits from the nerve, and crosses the meninges. It drains into the cavernous sinus, transmitting pressure to the episcleral veins by the superior ophthalmic vein. ${ }^{1,13}$ The third theory suggests that the CSF surrounding the optic nerve sheath at the point where the optic nerve enters the orbit could transmit an elevation in ICP throughout the orbit, thus elevating the IOP. ${ }^{2}$

Studies that assessed the relationship between IOP and ICP in both animals and humans found a slight effect of ICP on IOP, but mostly concluded that IOP provides no clinically useful estimate of ICP, $;^{1,12,14-17}$ however, the findings by Sajjadi et al ${ }^{2}$ are inconsistent with previous reports, as well as with ours. Those authors reported a tight correlation $(r=0.955)$ between IOP and ICP in a prospective cohort study among neurology inpatients at two university hospitals in Iran. IOP was measured by the Schiotz tonometer (Gulden Ophthalmics, Elkins Park, PA, USA) in all of the 50 study patients undergoing LPs for various neurologic workups. The authors proposed that IOP may be used instead of frequent LPs in the follow-up of patients with benign intracranial hypertension, and in patients with impaired consciousness after head trauma. Spentzas et al also reported a correlation between tonometric measurements of the IOP and transducer measurements of the ICP in the acute setting among children with traumatic brain injuries.

Our results showed that handheld tonometry was inadequate as a screening tool for elevated ICP. This would be in agreement with the suggestion of Hayreh, ${ }^{16}$ whereby an acute rise in ICP that was $>50 \mathrm{~cm} \mathrm{H}_{2} \mathrm{O}$ is required to cause significant elevations in IOP. He proposed that the subarachnoid space around the optic nerve is separated from the eye by a fibrous band that prevents the ICP transmission to the eye. Neither Hayreh's ${ }^{16}$ study nor that of Lehman et al ${ }^{17}$ found that IOP has a meaningful correlation with increased

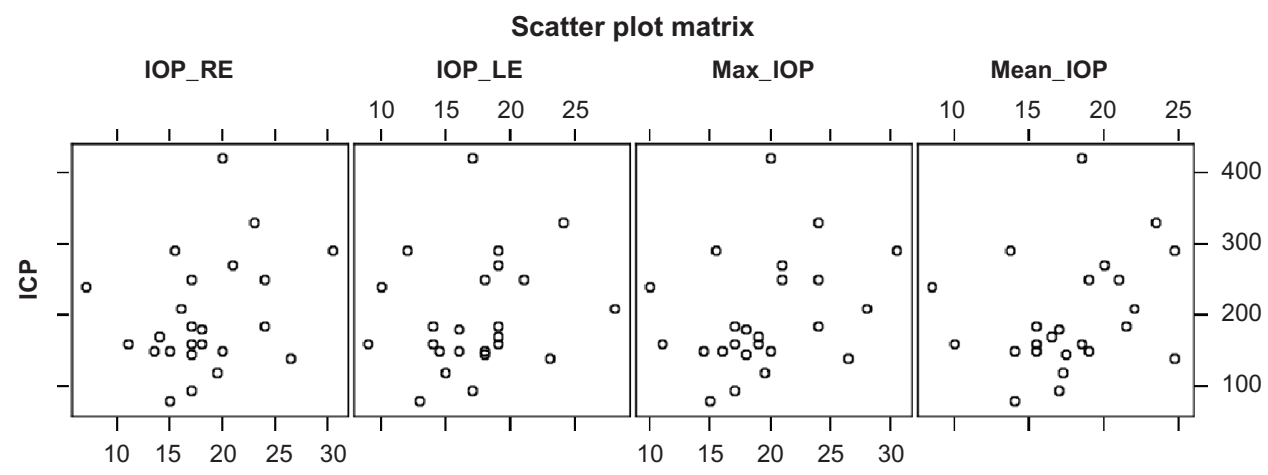

Figure I Scatter plot of IOP and ICP in the RE and LE.

Abbreviations: IOP, intraocular pressure; ICP, intracranial pressure; RE, right eye; LE, left eye. 
Table 2 ICP measurements in two groups of measured IOP (below and above $20 \mathrm{mmHg}$ )

\begin{tabular}{|c|c|c|c|c|c|c|}
\hline \multirow[t]{2}{*}{ IOP } & \multirow[t]{2}{*}{$\mathbf{n}$} & \multicolumn{4}{|l|}{ ICP } & \multirow[t]{2}{*}{$P$-value } \\
\hline & & Mean & SD & Minimum & Maximum & \\
\hline $\begin{array}{l}\text { I. Mean } \\
\qquad \mathrm{IOP} \leq 20\end{array}$ & 18 & 187.5 & 80.9 & 80 & 420 & \\
\hline $\begin{array}{l}\text { 2. Mean } \\
\qquad I O P>20\end{array}$ & 6 & 234.2 & 69.8 & 140 & 330 & 0.22 \\
\hline
\end{tabular}

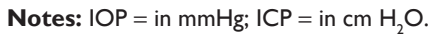

Abbreviations: ICP, intracranial pressure; IOP, intraocular pressure; SD, standard deviation.

ICP, unless the ICP pressures were extremely elevated. In that subset of patients, the clinical relevance of a bedside screening tool is most likely moot.

Other clinical studies support our results. Muchnok et a $1^{18}$ conducted a prospective observational study on 32 patients in the ED and found that the aggregate sensitivity of elevated IOP to predict elevated opening pressure was poor (sensitivity $24 \%, 95 \%$ confidence interval [CI] 9\%-48\%; specificity $63 \%$, $95 \%$ CI $32 \%-88 \%$; positive predictive value $28 \%$, 95\% CI 14\%-47\%; and negative predictive value $72 \%$, 95\% CI 53\%-96\%). IOP measurements correlated poorly with increased ICPs. The authors concluded that handheld tonometry is a poor screening tool for increased ICP in the ED. Han et a ${ }^{19}$ retrospectively reviewed the medical records of all patients who underwent LP between 1991 and 2007 in the neuron-ophthalmology clinic at the University of California, San Francisco, California, USA. Data for IOP and ICP were available for 55 patients. There was no correlation between IOP and ICP (Pearson correlation coefficient, $r=0.07$; $P=0.59$ ). The authors concluded that an IOP measurement is not a useful substitute for ICP measurement.

\section{Limitations}

This paper has few limitations; one is due to the small number of recruited patients and the statistical difficulties in drawing conclusions. Second, this study may have had some selection bias in that there probably were patients with elevated ICP who did not undergo an LP (eg, patients with malignancy, hydrocephalus, or intracranial hemorrhage diagnosed on imaging procedures). Third, there were only six patients in our study whose IOP was above $20 \mathrm{mmHg}$; this was smaller than the number reported by (Sajjadi et $\mathrm{al}^{2}$ and Han et $\mathrm{al}^{19}$ ). The fourth limitation is that all patients had their IOP measured by Tono-Pen, and not with Goldmann's tonometer, which is the gold standard method to measure IOP. While there are small differences in these two IOP measuring devices, studies have shown the accuracy of their measurements to be nearly equivalent. ${ }^{5-7}$ It has also been shown that handheld tonometry may better predict elevated ICP in patients whose ICP is very high, and there was only one such patient in our study group. In fact, handheld tonometry predicted elevated ICP in this patient who had bacterial meningitis and an ICP $>40 \mathrm{~cm} \mathrm{H}_{2} \mathrm{O}$.

\section{Conclusion}

Based on the results of this study, handheld ocular tonometry is a poor screening tool for increased ICP in patients in the ED or in the neurological department.

\section{Disclosure}

The authors report no conflicts of interest in this work.

\section{References}

1. Lashutka MK, Chandra A, Murray HN, Phillips GS, Hiestand BC. The relationship of intraocular pressure to intracranial pressure. Ann Emerg Med. 2004;43(5):585-591.

2. Sajjadi SA, Harirchian MH, Sheikhbahaei N, Mohebbi MR, Malekmadani MH, Saberi H. The relation between intracranial and intraocular pressures: study of 50 patients. Ann Neurol. 2006;59(5): 867-870.

3. Spentzas T, Henricksen J, Patters AB, Chaum E. Correlation of intraocular pressure with intracranial pressure in children with severe head injuries. Pediatr Crit Care Med. 2010;11(5):593-598.

4. Kirk T, Jones K, Miller S, Corbett J. Measurement of intraocular and intracranial pressure: is there a relationship? Ann Neurol. 2011;70(2): 323-326.

5. Rootman DS, Insler MS, Thompson HW, Parelman J, Poland D, Unterman SR. Accuracy and precision of the Tono-Pen in measuring intraocular pressure after keratoplasty and epikeratophakia and in scarred corneas. Arch Ophthalmol. 1988;106(12):1697-1700.

6. Mendelsohn AD, Forster RK, Mendelsohn SL, et al. Comparative tonometric measurements of eye bank eyes. Cornea. 1987;6(3):219-225.

7. Rao VJ, Gnanaraj L, Mitchell KW, Figueiredo FC. Clinical comparison of ocular blood flow tonometer, Tonopen, and Goldmann applanation tonometer for measuring intraocular pressure in postkeratoplasty eyes. Cornea. 2001;20(8):834-838.

8. Iester M, Mermoud A, Achache F, Roy S. New Tonopen XL: comparison with the Goldmann tonometer. Eye (Lond). 2001;15(Pt 1):52-58.

9. Kugler KK, Dick AR, Nelson SR. Intraocular and intraventricular pressures after glycerol ingestion. Arch Neurol. 1977;34(7):451.

10. Leung DY, Lam DS. The relationship of intraocular pressure to intracranial pressure. Ann Emerg Med. 2005;45(1):98-99; author reply 99-100.

11. Kumar V, Abbas AK, Fausto N, Aster J, editors. Pathology text, chapter 31. In: Robbins and Cotran Pathologic Basis of Disease, Professional Edition. Philadelphia, PA: Saunders; 2009:1373-1374.

12. Sheeran P, Bland JM, Hall GM. Intraocular pressure changes and alterations in intracranial pressure. Lancet. 2000;355(9207):899.

13. Salman MS. Can intracranial pressure be measured non-invasively? Lancet. 1997;350(9088):1367.

14. Smith RB, Aass AA, Nemoto EM. Intraocular and intracranial pressure during respiratory alkalosis and acidosis. Br J Anaesth. 1981;53(9):967-972.

15. Czarnik T, Gawda R, Latka D, Kolodziej W, Sznajd-Weron K, Weron R. Noninvasive measurement of intracranial pressure: is it possible? J Trauma. 2007;62(1):207-211.

16. Hayreh SS. Non-invasive measurement of intracranial pressure. Lancet. 1998;351(9101):524-525. 
17. Lehman RA, Krupin T, Podos SM. Experimental effect of intracranial hypertension upon intraocular pressure. J Neurosurg. 1972;36(1): 60-66.

18. Muchnok T, Deitch K, Giraldo P. Can intraocular pressure measurements be used to screen for elevated intracranial pressure in emergency department patients? J Emerg Med. 2012;43(3):532-537.
19. Han Y, McCulley TJ, Horton JC. No correlation between intraocular pressure and intracranial pressure. Ann Neurol. 2008;64(2):221-224.

\section{Publish your work in this journal}

Clinical Ophthalmology is an international, peer-reviewed journal covering all subspecialties within ophthalmology. Key topics include: Optometry; Visual science; Pharmacology and drug therapy in eye diseases; Basic Sciences; Primary and Secondary eye care; Patien Safety and Quality of Care Improvements. This journal is indexed on

Submit your manuscript here: http://www.dovepress.com/clinical-ophthalmology-journal

\section{Dovepress}

PubMed Central and CAS, and is the official journal of The Society of Clinical Ophthalmology (SCO). The manuscript management system is completely online and includes a very quick and fair peer-review system, which is all easy to use. Visit http://www.dovepress.com/ testimonials.php to read real quotes from published authors. 